Bradley, C. C., and Bowles, D. 1967. Strength-load ratio. An index of deep slab avalanche conditions. (In Ōura, $\mathrm{H}$., ed. Physics of snow and ice: international conference on low temperature science. . . I966. ... Proceedings, Vol. I, Pt. 2. [Sapporo], Institute of Low Temperature Science, Hokkaido University, p. I 243-53.)

Sommerfeld, R. A. 1969 . The role of stress concentration in slab avalanche release. fournal of Glaciology, Vol. 8, No. 54 , p. $45^{1-62}$.

\title{
SIR, The role of stress concentration in slab avalanche release: reply to the comments of Dr C. C. Bradley
} and $\operatorname{Dr}$ D. Bowles

I certainly cannot argue with the careful observations reported by Dr Bradley and Dr Bowles. Our basic disagreement concerns the time sequence of events which lead to snow failure. Any failure criterion would predict the initiating event, so the time sequence is of prime importance. As I understand it Bradley and Bowles model would have a lower layer, which is weak in compression, fail under a compressive load. Then the total load would be thrown onto the upper layers bending them so that they fail in tension. Another possibility would follow this sequence. First a lower layer, in a pack under significant elastic tension would fail in compression in a small spot. The increased gravitational load and the release of elastic energy would cause the basal failure to propagate from the point of initial failure until the release of elastic energy was sufficient to cause tensile failure along a line at some distance from the initial disturbance. A third possibility, consistent with the model which I proposed, is as follows. A snow pack slowly subsides because of mass loss occurring at a layer forming depth hoar. The subsidence causes increased tensile stresses in the upper layers. The snow fails, in tension, at some point on the surface. The failure propagates downward until it reaches the weak layer where it propagates laterally, aided by the increased gravitational load and by the release of elastic energy.

Other models might be postulated which lead to the same result. If some way could be found to determine the relative importance of the different models, we would have a significant advance in our understanding of avalanche release.

\section{U.S. Forest Service,}

R. A. Sommerfeld

\author{
Rocky Mountain Forest and Range Experiment Station, \\ 240 West Prospect, \\ Fort Collins, Colorado 80521, U.S.A. \\ 13 February 1970
}

